\title{
STUDI PERBANDINGAN ARSITEKTUR TRADISIONAL ANGKOLA DENGAN ARSITEKTUR TRADISIONAL BATAK TOBA DITINJAU DARI STRUKTUR BANGUNAN
}

\author{
Wengky Billy Putra Giawa( ${ }^{(1)}$, Ir. Raimundus Pakpahan, M.T ${ }^{(2)}$, Yulianto,ST.,M.Eng ${ }^{(3)}$ \\ ((1)Mahasiswa, Prodi Arsitektur, Fakultas Teknik, Universitas Katolik Santo Thomas Sumatera Utara \\ (2) Staff Pengajar, Prodi Arsitektur, Fakultas Teknik, Universitas Katolik Santo Thomas Sumatera Utara \\ Email: pakpahanray@yahoo.co.id \\ 3) Staff Pengajar, Prodi Arsitektur, Fakultas Teknik, Universitas Katolik Santo Thomas Sumatera Utara \\ Email: yulibean97@gmail.com
}

\begin{abstract}
The Batak are the majority in North Sumatra. The Batak tribe even has another sub-tribe, namely Toba Batak, Karo Batak, Simalungun Batak, Mandailing Batak and Angkola Batak. Every Batak tribe has its own distinctive culture and identity. Batak tribes have traditional buildings which are traditional Batak architectural identities. The diversity of the Batak tribe caused the phenomenon of visual aspect equality in traditional buildings because of the effects of secession and cultural integration. The Toba Batak architecture has the concept of a stilt house and pointed gable construction in both directions and a peg and pen structure system is evidence of similarities with Angkola Batak architecture. Angkola Bataks are part of the Batak tribe. Angkola Batak is a tribe in the area of South Tapanuli. The Toba Batak is the center of the Batak culture. The Toba Batak has one of the traditional Sopo buildings, namely Sopo. Sopo functions as a barn, but also an art venue and meeting place. Angkola Batak has one traditional building that represents the traditional architecture of the Angkola Batak namely Sopo Godang. Serves as a meeting place for the king and the people. It is a place where tradition is based on Dalihan Na Tolu which produces consensus and mutual agreement (The King and People). Sopo Godang is a part of traditional Batak architecture that needs to be preserved. The benefit of this study is to collect data on traditional Angkola Batak architecture and data on structures that are characteristic of the Angkola Batak.
\end{abstract}

Keywords :Batak, Sopo Godang, Traditional Architecture

\begin{abstract}
Abstrak
Suku Batak merupakan mayoritas di daerah Sumatera Utara. Suku Batak bahkan memiliki sub suku lagi yakni Batak Toba, Batak Karo, Batak Simalungun, Batak Mandailing dan Batak Angkola. Setiap suku Batak memiliki budaya ciri khas dan identitas tersendiri. Suku Batak memiliki Bangunan tradisional yang merupakan identitas arsitektur tradisional Batak. Keberagaman suku Batak menyebabkan adanya fenomena persamaan aspek visual pada bangunan adat karena akibat pemisahan diri maupun penggabungan budaya. Arsitektur Batak Toba memiliki konsep rumah panggung dan konstruksi atap pelana yang runcing di kedua arah serta sistem struktur pasak dan pen adalah bukti adanya kesamaan dengan arsitektur Batak Angkola. Batak Angkola merupakan bagian suku Batak. Batak Angkola adalah suku yang berada di daerah Tapanuli Selatan. Batak Toba merupakan pusat kebudayaan Batak. Batak Toba memiliki salah satu bangunan adat sopo yaitu sopo. Sopo berfungsi sebagai lumbung, tetapi juga tempat kesenian dan tempat pertemuan. Batak Angkola memiliki satu bangunan adat yang mewakili arsitektur tradisional Batak Angkola yakni Sopo Godang. Berfungsi sebagai tempat pertemuan raja dengan rakyat. Merupakan tempat dimana tradisi berlandaskan Dalihan Na Tolu yang menghasilkan mufakat dan kesepakatan bersama (Raja dan Rakyat). Sopo Godang merupakan bagian arsitektur tradisional Batak yang perlu dilestarikan. Manfaat penelitian ini adalah mengumpulkan data arsitektur tradisional Batak Angkola dan data tentang struktur yang menjadi ciri khas Batak Angkola.
\end{abstract}

Kata kunci ; Batak, Sopo Godang, Arsitektur Tradisional 


\section{Pendahuluan}

Provinsi Sumatera Utara beribukota di Medan, yang kebanyakan dihuni oleh suku Batak. Batak sendiri merupakan salah satu suku di Indonesia, dengan jumlah penduduk yang besar setelah suku Jawa. Batak juga dikelompokkan menjadi beberapa sub suku lagi. Yaitu Batak Toba, Karo, Simalungun, Angkola, Pakpak, dan Mandailing. Masing-masing sub suku tersebut memiliki adat budaya yang berbeda-beda. Perbedaan ini bisa terlihat dari desain rumah adatnya. Dari aspek visual, beberapa bangunan tradisional Batak diantaranya terlihat mirip karena bentuk dan juga strukturnya. Begitu juga halnya bangunan tradisional Angkola yang terlihat mirip dengan bangunan tradisional Batak Toba. Hal itu terlihat dari bentuk atap segitiga dan bentuknya misalnya bahan materialnya atap menggunakan ijuk. Sama halnya dengan struktur yang menggunakan sistem persambungan kayu yakni konstruksi rangka tersusun dan menggunakan kolom yang berbentuk bulat. Adapun dugaan sementara yakni terdapat perbedaan dan persamaan arsitektur Batak toba dengan arsitektur batak angkola ditinjau dari struktur. Untuk itu perlu dikaji dan diteliti aspek-aspek bangunan tradisional Batak Angkola ditinjau dari strukturnya.

\section{Tinjauan Pustaka}

\section{Arsitektur Tradisional Batak Toba}

Konsep Kebudayaan dan Kosmologi

Pokok budaya Batak Toba yang penting termanifestasikan pada ungkapan budaya sebagai berikut :

1. Tunggal Panaluan, yaitu tongkat yang dipergunakan pad upacara-upacara adat.

2. Bendera Gajah Dompak yang merupakan tanda dalam bentuk wajah manusia raksasa pada sebatang kayu berfungsi sebagai sarana penolak bala atau roh jahat yang bakal mengganggu penghuni rumah.

3. Singa rumah batak berupa ornament ukiran kayu (gorga) yang memberi arti kewibawaan, kebenaran dan keadilan hukum.

4. Bakkara

5. Dalihan Na Tolu yang berarti tungku tiga kaki. Artian yang signifikan dengan konsep dalihan na tolu adalah bahwa keseluruhan alam semesta merupakan satu kesatuan yang tak terpisahkan dengan penguasa alam. Tiap bagian alam adalah juga keseluruhan semesta. Keseluruhan alam semesta ini dinyatakan dalam agama dulu yaitu kepercayaan orang Batak terhadap Dewa tertinggi (Mula Jadi Na Bolon). Alam semesta tersebut mempunyai tiga aspek yang penting yaitu dunia langit, dunia bumi dan dunia di bawah bumi.

\section{Konstruksi Bangunan Tradisional Batak Toba}

1. Batu pondasi (Batu Ojahan)

Keseluruhan Rumah Batak ditopang oleh pondasi yang dinamai 'batu ojahan'. Batu pondasi ini terletak langsung di atas tanah sebagai pijakan tiang rumah. Jumlah batu pondasi sesuai dengan jumlah tiang rumah.

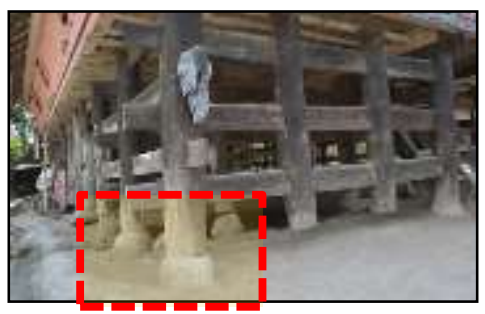

Gambar. 1 Batu Pondasi

Sumber : Dokumentasi Kelompok

\section{Tiang (Basiha)}

Rumah Batak terdiri atas tiang tiang yang besar dan kokoh. Tiang-tiang ini umumnya bulat. Tiang yang bulat dinamai secara khusus 'basiha'. Tiang rumah batak kurang lebih 1.70 meter.

Jumlah keseluruhan tiang rumah ada 12 buah tiang yang panjang. Konon, jumlah ini menggambarkan jumlah bulan dalam 1 tahun. Ada dua jenis tiang, yaitu tiang panjang (basiha ganjang), dan tiang pendek (basiha pandak). Tiang yang panjang ialah yang menyentuh batu pondasi sampai ke palang atas penahan atap. Selain itu ada 20 buah tiang yang pendek yang mendukung keseluruhan badan rumah. Tiang yang pendek ialah tiang yang menyentuh batu pondasi dan lantai rumah. 


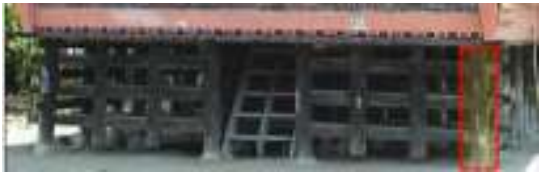

Gambar. 2 Tiang (Basiha)

Sumber : Dokumentasi Kelompok.

\section{Pasak (Ransang, Tustus)}

Pasak yang biasa dalam rumah batak disebut 'ransang'. Ransang dibuat dari sebilah kayu panjang dengan ukuran $15 \times 3 \mathrm{~cm}$. pasak pasak ini menusuk tiang pada bagian tengah kiri dan kanan.biasanya ada tiga sampai empat baris ransang dari bawah sampai ke atas.

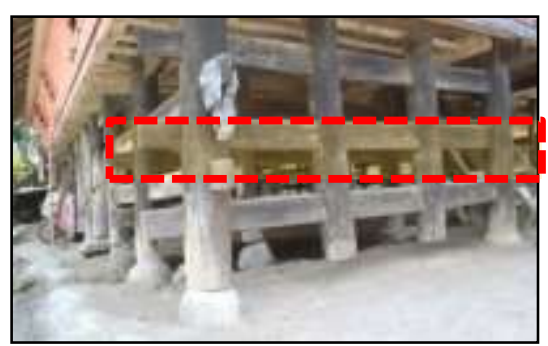

Gambar.3 Pasak (Ransang)

Sumber : Dokumentasi Kelompok

4. Tangga (Balatuk)

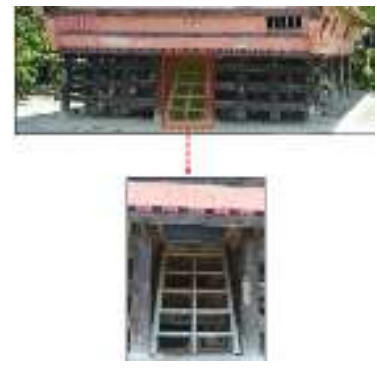

\section{Gambar. 4 Tangga pada rumah Sitolumbea}

Sumber : Dokumentasi Kelompok

Jumlah anak tangga mempunyai arti status sosial. Dalam masyarakat batak toba rumah yang mempunyai anak tangga ganjil adalah rumah tangga bebas, raja huta atau marga yang membuka kampung (sipungka huta). Sedangkan rumah dengan anak tangga genap menandakan bahwa orang yang mendiami rumah tersebut adalah budak atau keturunan budak (hatoban).

Lampiran.
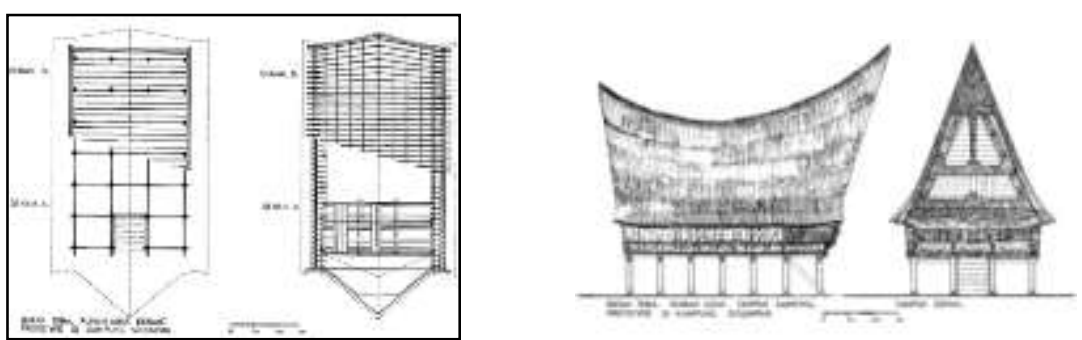

Gambar. 5 Sketsa denah, tampak samping, dan tampak depan Rumah Bolon Sumber : Arsitektur dan Sosial budaya Sumatera Utara,2013, hal 100 


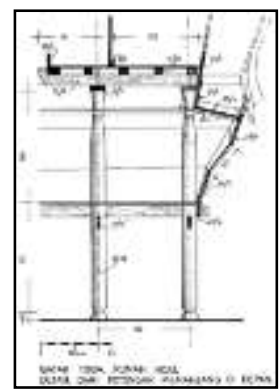

Gambar.6 Sketsa detail potongan tiang Rumah Bolon Sumber : Arsitektur dan Sosial budaya Sumatera Utara,2013,hal 103
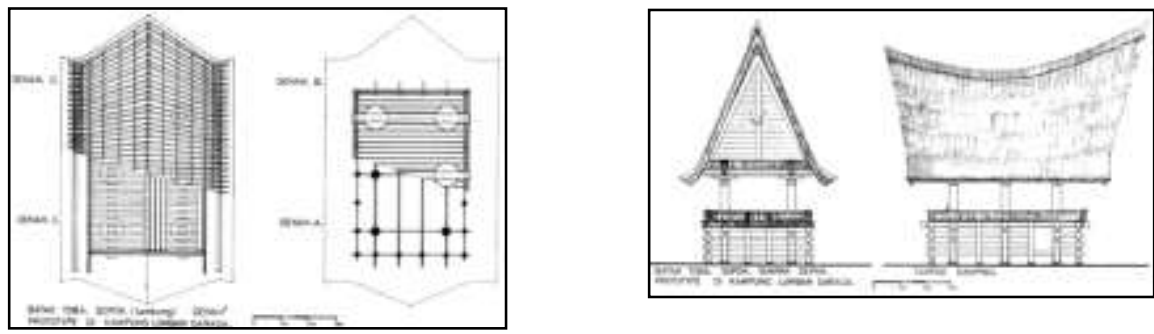

Gambar 7 Sketsa denah, tampak depan dan tampak samping Sopo Sumber : Arsitektur dan Sosial budaya Sumatera Utara,2013,hal 102
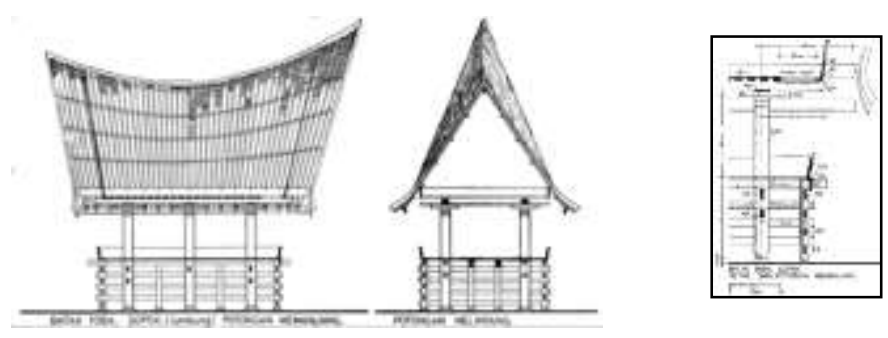

Gambar 8 Potongan Sopo dan detail.

Sumber : Arsitektur dan Sosial budaya Sumatera Utara,2013, hal 102

\section{Arsitektur Tradisional Angkola}

Sopo Godang pada Suku Batak Angkola berfungsi sebagai tempat Raja dan masyarakat untuk Mufakat Dalihan na Tolu (adat) dan Martahi (kepentingan desa). Disetiap desa atau yang disebut "huta" pada suku angkola harus mempunyai sopo godang yang letaknya berada di tengah-tengah desa.

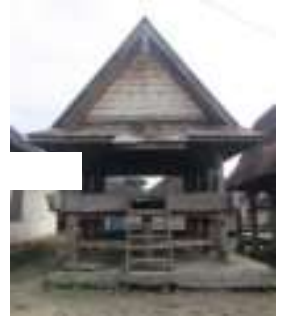

(a)

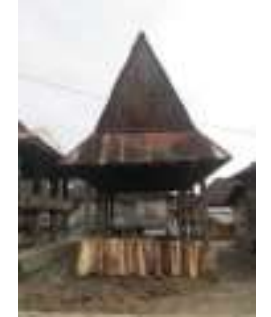

(b)

Gambar 9 a. Sopo Godang yang telah disahkan dengan adat b. Sopo Godang yang belum disahkan dengan adat Sumber : Dokumen Pribadi

Sopo Godang merupakan bangunan peninggalan suku batak angkola yang asli. Sopo Godang yang asli terletak di Desa Bunga Bondar, Sipirok. Sopo Godang tidaklah berdinding penuh, melainkan hanya sebagai tempat bersender sehingga berkesan terbuka dan tidak ada yang perlu disembunyikan dari masyarakat desa. 


\section{Metodologi Penelitian}

Metode penilitian yang digunakan adalah penilitian deskriptif - komparatif. Penilitian komparatif adalah sejenis penelitian deskriptif yang ingin mencari jawab secara mendasar tentang sebab-akibat, dengan menganalisis faktor- faktor penyebab terjadinya ataupun munculnya suatu fenomena tertentu.

\section{Analisa}

Analisa ini dilakukan dengan melakukan perbandingan berdasarkan hasil survey dan pengumpulan data di lapangan. Data hasil wawancara merupakan data primer yang didapatkan. Metode yang digunakan menggunakan analisa komparatif. Metode ini membandingkan struktur bangunan tradisional suku batak toba dengan bangunan tradsional suku batak angkola. 
Jurnal Arsitektur ALUR - Vol.2 No.2 September 2019

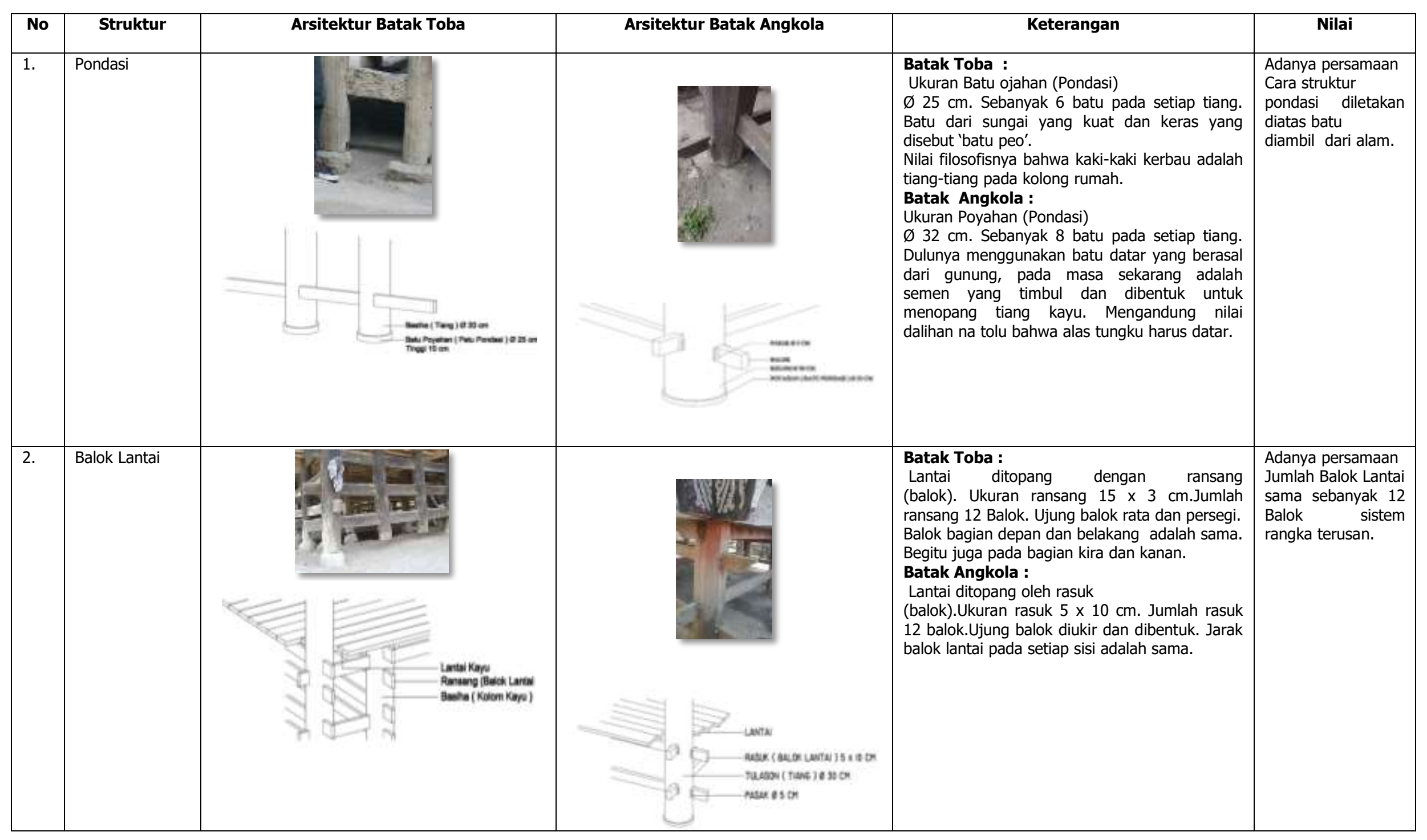


Jurnal Arsitektur ALUR - Vol.2 No.2 September 2019

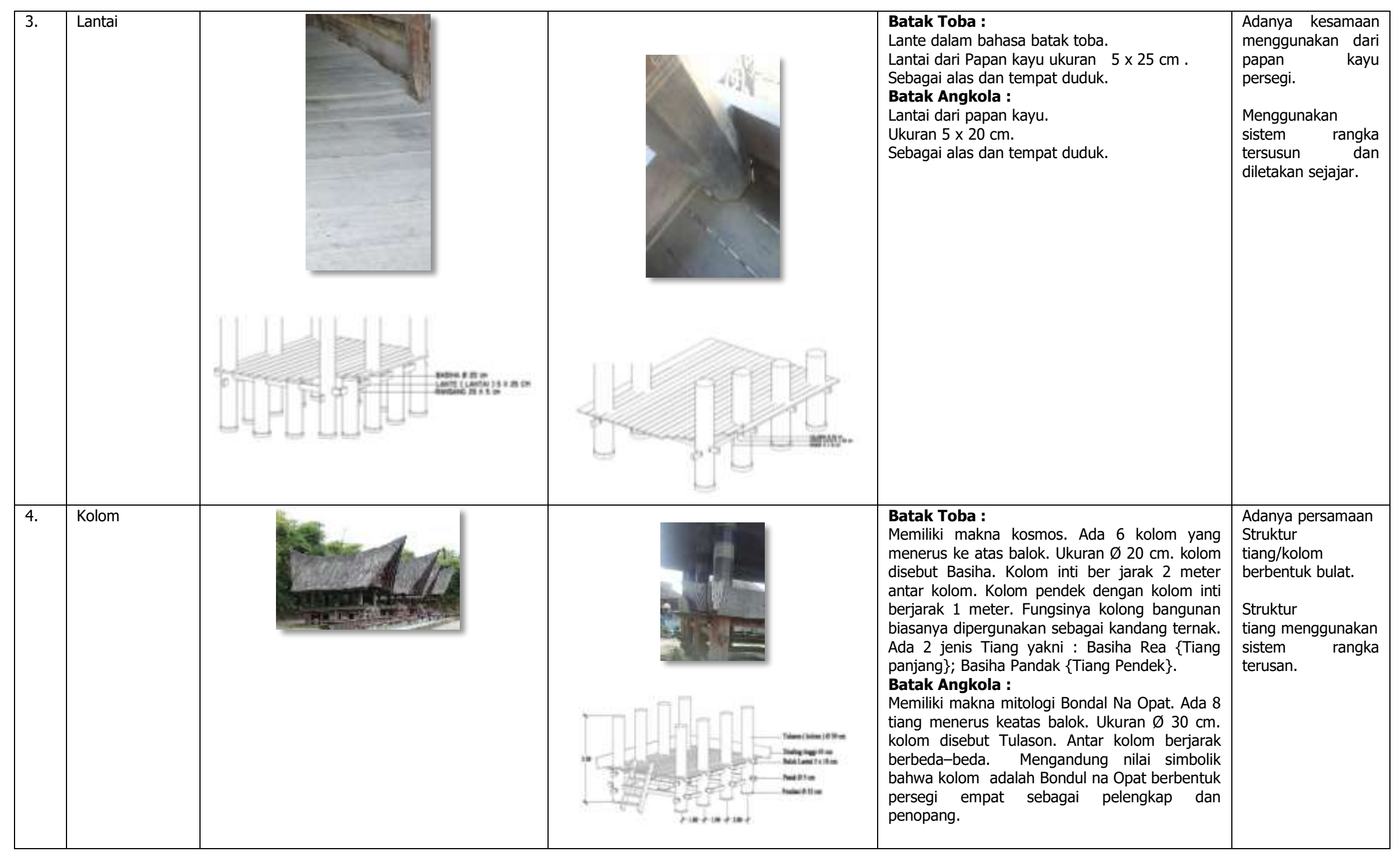


Jurnal Arsitektur ALUR - Vol.2 No.2 September 2019

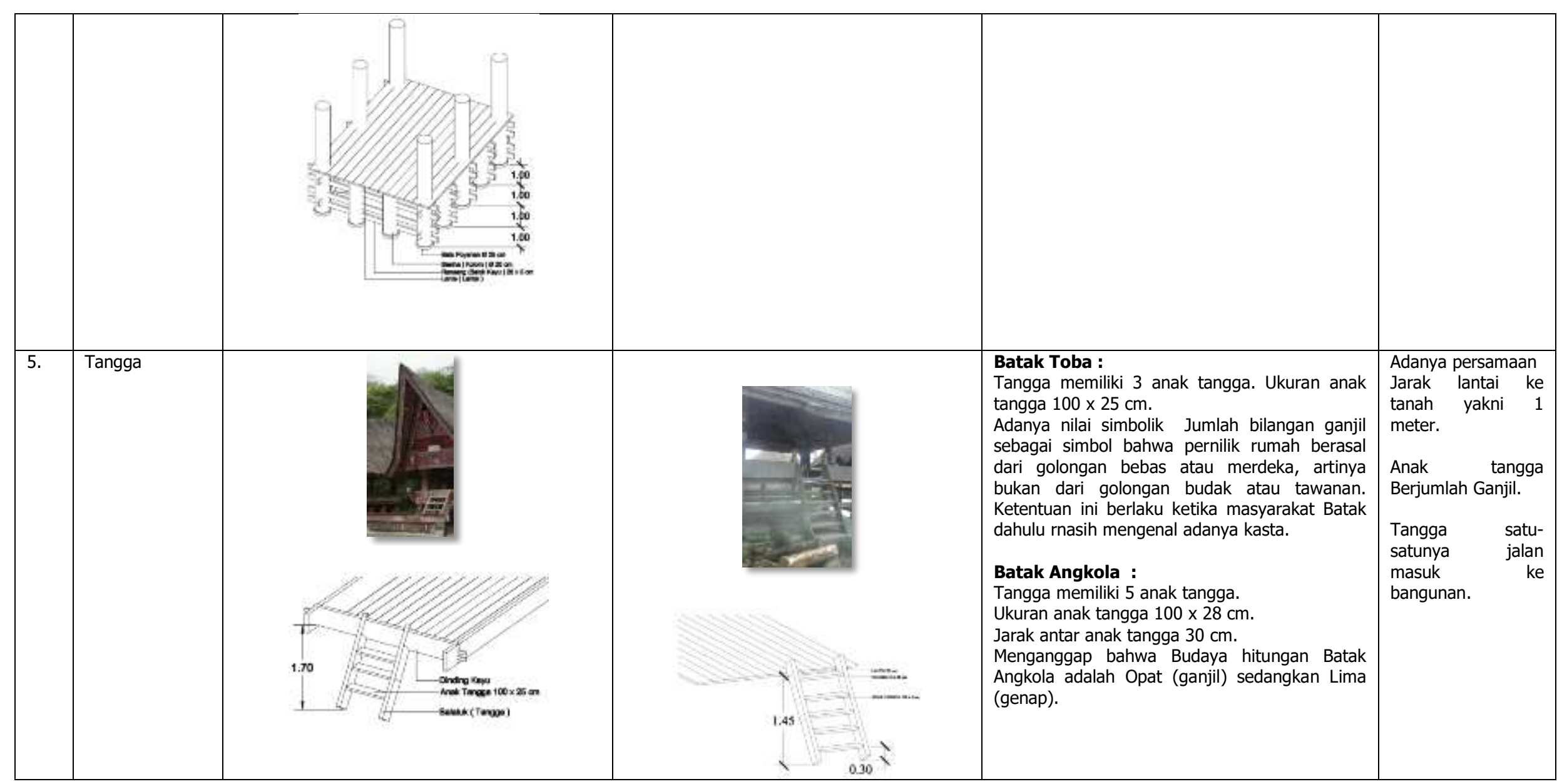


Jurnal Arsitektur ALUR - Vol.2 No.2 September 2019

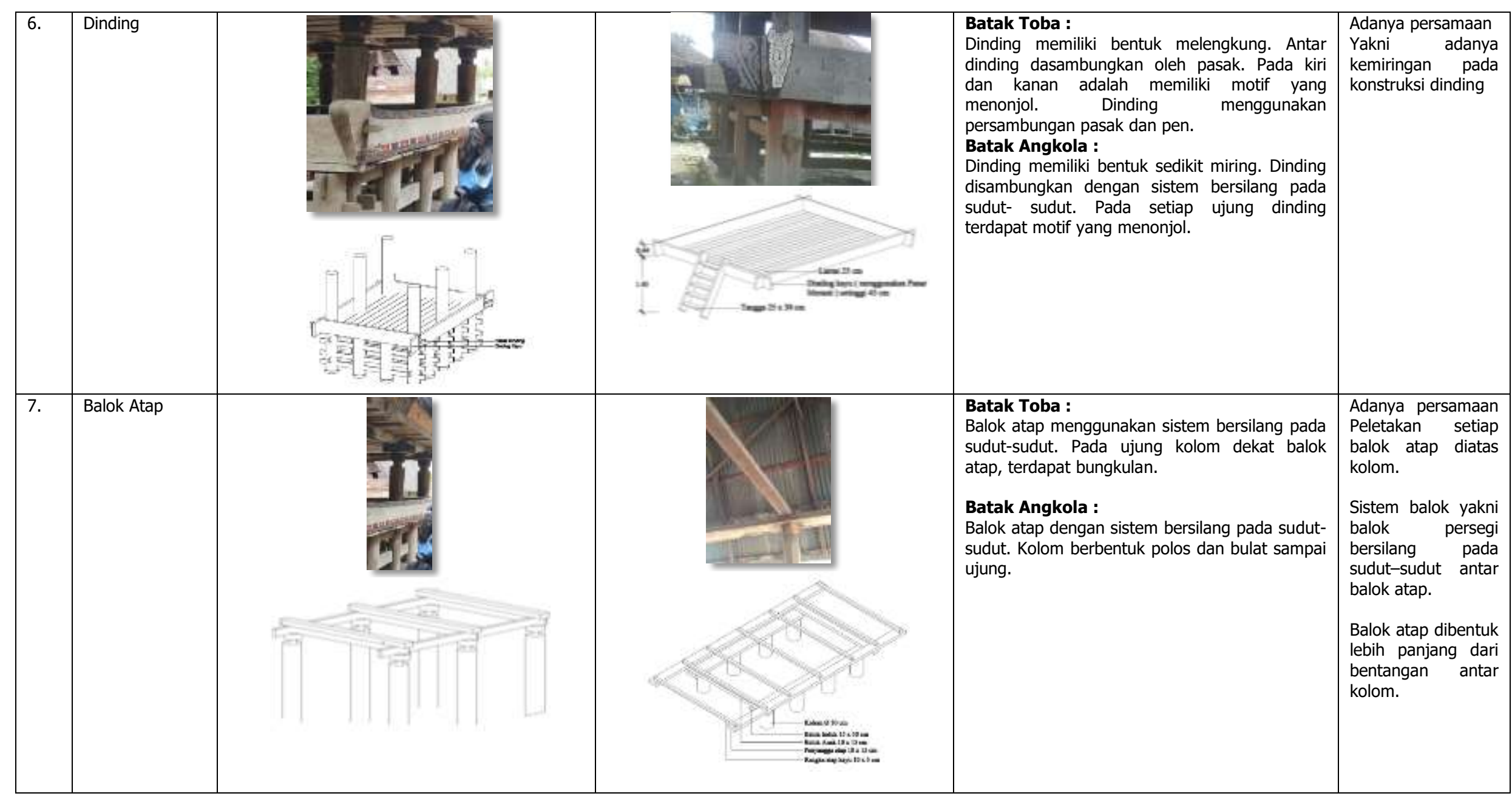




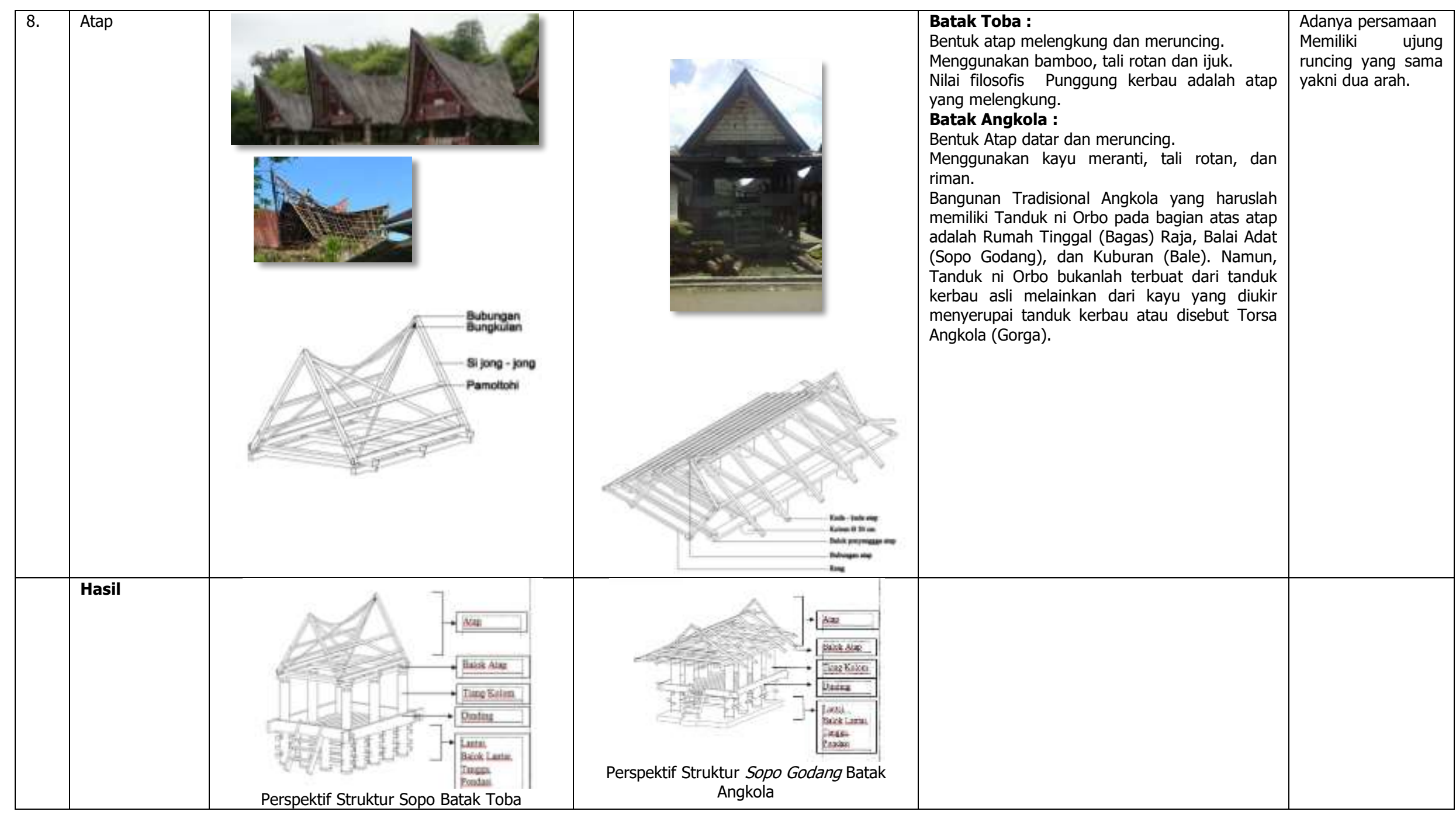




\section{Kesimpulan dan Saran}

Dari hasil penelitian diatas dapat disimpulkan bahwa :

1. Arsitektur tradisional Batak toba memiliki perbedaan dan persamaan dengan arsitektur Batak Angkola. Pembangunan rumah adat tradisional berdasarkan prinsip hidup masing-masing daerah.

2. Sopo godang merupakan arsitektur tradisional peningggalan kuno masyarakat batak angkola. Bangunan ini yang menunjukan identitas Batak angkola yakni berlandaskan adat kesepakatan, mufakat dan musyawarah untuk kepentingan bersama atau disebut Dalihan Na Tolu.

3. Struktur dan konstruksi bangunan tradisional di Desa Bunga Bondar, Sipirok memiliki perbedaan dengan Arsitektur Batak Toba, antara lain :

a. Pondasi ;

Batak Toba : Ukuran Batu ojahan (Pondasi) $\varnothing 25 \mathrm{~cm}$. Sebanyak 6 batu pada setiap tiang. Batu dari sungai yang kuat dan keras yang disebut 'batu peo'. Nilai filosofisnya bahwa kaki-kaki kerbau adalah tiang-tiang pada kolong rumah. Tujuannya supaya pemilik rumah selamat dan banyak rejeki di tempat yang baru.

Batak Angkola : Ukuran Poyahan (Pondasi) $\varnothing 32 \mathrm{~cm}$. Sebanyak 8 batu pada setiap tiang. Dulunya menggunakan batu datar yang berasal dari gunung, pada masa sekarang adalah semen yang timbul dan dibentuk untuk menopang tiang kayu. Mengandung nilai dalihan na tolu bahwa alas tungku harus datar.

b. Balok lantai ;

Batak Toba : Lantai ditopang dengan ransang (balok). Ukuran ransang $15 \times 3 \mathrm{~cm}$. Jumlah ransang 12 Balok. Ujung balok rata dan persegi. Balok bagian depan dan belakang adalah sama. Begitu juga pada bagian kira dan kanan.

Batak Angkola : Lantai ditopang oleh rasuk (balok). Ukuran rasuk $5 \times 10 \mathrm{~cm}$. Jumlah rasuk 12 balok. Ujung balok diukir dan dibentuk. Jarak balok lantai pada setiap sisi adalah sama.

c. Lantai ;

Batak Toba : Lante dalam bahasa batak toba. Lantai dari Papan kayu ukuran $5 \times 25 \mathrm{~cm}$. Sebagai alas dan tempat duduk.

Batak Angkola : Lantai dari papan kayu. Ukuran 5 × $20 \mathrm{~cm}$. Sebagai alas dan tempat duduk.

d. Kolom ;

Batak Toba : Memiliki makna kosmos. Ada 6 kolom yang menerus ke atas balok. Ukuran $\varnothing 20 \mathrm{~cm}$. kolom disebut Basiha. Kolom inti ber jarak 2 meter antar kolom. Kolom pendek dengan kolom inti berjarak 1 meter. Fungsinya kolong bangunan biasanya dipergunakan sebagai kandang ternak. Ada 2 jenis Tiang yakni : Basiha Rea \{Tiang panjang\}; Basiha Pandak \{Tiang Pendek\}.

Batak Angkola : Memiliki makna mitologi Bondal Na Opat. Ada 8 tiang menerus keatas balok. Ukuran $\varnothing 30 \mathrm{~cm}$. kolom disebut Tulason. Antar kolom berjarak berbeda-beda. Mengandung nilai simbolik bahwa kolom adalah Bondul na Opat berbentuk persegi empat sebagai pelengkap dan penopang.

e. Tangga ;

Batak Toba : Tangga memiliki 3 anak tangga. Ukuran anak tangga $100 \times 25 \mathrm{~cm}$. Adanya nilai simbolik Jumlah bilangan ganjil sebagai simbol bahwa pernilik rumah berasal dari golongan bebas atau merdeka, artinya bukan dari golongan budak atau tawanan. Ketentuan ini berlaku ketika masyarakat Batak dahulu rnasih mengenal adanya kasta.

Batak Angkola : Tangga memiliki 5 anak tangga. Ukuran anak tangga $100 \times 28 \mathrm{~cm}$. Jarak antar anak tangga $30 \mathrm{~cm}$. Menganggap bahwa Budaya hitungan Batak Angkola adalah Opat (ganjil) sedangkan Lima (genap).

f. Dinding ;

Batak Toba : Dinding memiliki bentuk melengkung. Antar dinding dasambungkan oleh pasak. Pada kiri dan kanan adalah memiliki motif yang menonjol. Dinding menggunakan persambungan pasak dan pen.

Batak Angkola : Dinding memiliki bentuk sedikit miring. Dinding disambungkan dengan sistem bersilang pada sudut-sudut. Pada setiap ujung dinding terdapat motif yang menonjol.

g. Balok atap ;

Batak Toba : Balok atap menggunakan sistem bersilang pada sudut-sudut. Pada ujung kolom dekat balok atap, terdapat bungkulan.

Batak Angkola : Balok atap dengan sistem bersilang pada sudut-sudut. Kolom berbentuk polos dan bulat sampai ujung.

h. Atap ;

Batak Toba : Bentuk atap melengkung dan meruncing. Menggunakan bamboo, tali rotan dan ijuk. Nilai filosofis Punggung kerbau adalah atap yang melengkung.

Batak Angkola : Bentuk Atap datar dan meruncing. Menggunakan kayu meranti, tali rotan, dan riman. Bangunan Tradisional Angkola yang haruslah memiliki Tanduk ni Orbo pada bagian atas atap 
adalah Rumah Tinggal (Bagas) Raja, Balai Adat (Sopo Godang), dan Kuburan (Bale). Namun, Tanduk ni Orbo bukanlah terbuat dari tanduk kerbau asli melainkan dari kayu yang diukir menyerupai tanduk kerbau atau disebut Torsa Angkola (Gorga).

4. Struktur dan konstruksi bangunan tradisional di Desa Bunga Bondar, Sipirok memiliki persamaan dengan Arsitektur Batak Toba, antara lain :

a. Pondasi ; Memiliki proses konstruksi dengan menggunakan pondasi batu yang ditanam lalu diletakan tiang diatasnya.

b. Balok Lantai ; Adanya persamaan jumlah balok sebanyak 12 balok dengan sistem rangka terusan.

c. Lantai ; Adanya kesamaan menggunakan dari papan kayu persegi. Menggunakan sistem rangka tersusun dan diletakan sejajar.

d. Kolom ; Adanya persamaan menggunakan kolom berbentuk bulat. Kolom menggunakan sistem rangka terusan.

e. Tangga ; Merupakan jalur satu-satunya masuk dan keluar bangunan. Anak tangga berjumlah ganjil..

f. Dinding ; Dinding hanya sebagai pembatas lebih mengutamakan sifat terbuka. Adanya kemiringan pada konstruksi dinding.

g. Balok atap ; Balok atap sistem rangka tersusun untuk menopang kerangka atap.

h. Atap ; Atap mengunakan konstruksi tradisional dengan sistem persambungan kayu. Memiliki ujung runcing yang sama yakni dua arah.

5. Ada pun keterbatasan pembuatan laporan penelitian serta dalam pengumpulan data yakni melakukan pengukuran pada struktur atap karena tidak dapat dijangkau dan kurangnya data informasi mengenai struktur Batak Angkola.

\section{Saran}

Dari studi yang diadakan, maka dapat disarankan bahwa sebagai berikut untuk pengelola adalah masyarakat desa Bunga Bondar agar tetap menjaga dan merawat Sopo Godang sebagai bagian dari kehidupan desa setempat. Untuk pemerintah agar menambah fasilitas informasi tentang arsitektur tradisional angkola sehingga tetap menjaga kelestarian budaya setempat.

\section{Daftar Pustaka}

Arikunto, S, 1987, Prosedur Penelitian Suatu Pendekatan Praktik, Bina Aksara, Jakarta.

Darmadi, H 2014, Metode Penelitian Pendidikan Dan Social, Alfabeta Cv, Bandung.

Frick, H 1983, I/mu Konstruksi Bangunan Kayu, Kanisius, Yogyakarta.

Manurung, M 2018, Identifikasi Bangunan Tradisional Sipirok ( Tapanuli Selatan ), Makalah Penelitian, Medan,

Praptiningrum, U 2009, Glosari Arsitektur, Andi Offset, Yogyakarta

Wahid, J \& Alamsyah, B 2013, Arsitektur dan Sosial budaya Sumatera Utara, Graha Ilmu, Yogyakarta. 